\title{
Systematic review and network meta-analysis of interventions for fibromyalgia: a protocol
}

\author{
Jason W Busse ${ }^{1,2^{*}}$, Shanil Ebrahim², Gaelan Connell ${ }^{3}$, Eric A Coomes ${ }^{4}$, Paul Bruno ${ }^{5}$, Keshena Malik ${ }^{6}$, \\ David Torrance ${ }^{3}$, Trung $\mathrm{Ngo}^{3}$, Karin Kirmayr ${ }^{7}$, Daniel Avrahami ${ }^{3}$, John J Riva ${ }^{2,8}$, Peter Struijs ${ }^{9}$, David Brunarski ${ }^{10}$, \\ Stephen J Burnie ${ }^{3}$, Frances LeBlanc ${ }^{3}$, Ivan A Steenstra ${ }^{11,12}$, Quenby Mahood ${ }^{11}$, Kristian Thorlund ${ }^{2,13}$, \\ Victor M Montori ${ }^{14}$, Vishalini Sivarajah ${ }^{15}$, Paul Alexander ${ }^{2}$, Milosz Jankowski $^{16}$, Wiktoria Lesniak ${ }^{16,17}$, \\ Markus Faulhaber ${ }^{2,8}$, Małgorzata M Bała ${ }^{16,17}$, Stefan Schandelmaier ${ }^{18}$ and Gordon H Guyatt ${ }^{2}$
}

\begin{abstract}
Background: Fibromyalgia is associated with substantial socioeconomic loss and, despite considerable research including numerous randomized controlled trials (RCTs) and systematic reviews, there exists uncertainty regarding what treatments are effective. No review has evaluated all interventional studies for fibromyalgia, which limits attempts to make inferences regarding the relative effectiveness of treatments.

Methods/design: We will conduct a network meta-analysis of all RCTs evaluating therapies for fibromyalgia to determine which therapies show evidence of effectiveness, and the relative effectiveness of these treatments. We will acquire eligible studies through a systematic search of CINAHL, EMBASE, MEDLINE, AMED, HealthSTAR, PsychINFO, PapersFirst, ProceedingsFirst, and the Cochrane Central Registry of Controlled Trials. Eligible studies will randomly allocate patients presenting with fibromyalgia or a related condition to an intervention or a control. Teams of reviewers will, independently and in duplicate, screen titles and abstracts and complete full text reviews to determine eligibility, and subsequently perform data abstraction and assess risk of bias of eligible trials. We will conduct meta-analyses to establish the effect of all reported therapies on patient-important outcomes when possible. To assess relative effects of treatments, we will construct a random effects model within the Bayesian framework using Markov chain Monte Carlo methods.

Discussion: Our review will be the first to evaluate all treatments for fibromyalgia, provide relative effectiveness of treatments, and prioritize patient-important outcomes with a focus on functional gains. Our review will facilitate evidence-based management of patients with fibromyalgia, identify key areas for future research, and provide a framework for conducting large systematic reviews involving indirect comparisons.
\end{abstract}

Keywords: Fibromyalgia, Systematic review, Network meta-analysis, Multiple treatment comparison, Randomized controlled trials

\section{Background}

Fibromyalgia is a syndrome characterized by chronic widespread pain and excessive tenderness at 11 of 18 specific muscle-tendon sites, for which no clear cause can be found [1]. Approximately $2 \%$ of the general population in the United States suffers from fibromyalgia, with women

\footnotetext{
* Correspondence: bussejw@mcmaster.ca

'Department of Anesthesia, McMaster University, 1200 Main Street West, Hamilton, Ontario L8S 4K1, Canada

${ }^{2}$ Department of Clinical Epidemiology and Biostatistics, McMaster University, 1200 Main Street West, Hamilton, Ontario L8S 4K1, Canada

Full list of author information is available at the end of the article
}

affected ten times more often than men [2]. Similar prevalence rates have been reported in Canada (3.3\%), Brazil $(4.4 \%)$ and Western European countries, including Germany (3.2\%), Spain (2.4\%), Italy (2.2\%), Sweden (2.5\%), France (1.4\%), Italy (3.7\%) and Portugal (3.6\%) [3-8]. Treatment directed towards fibromyalgia is highly variable and long-term prospective observational studies have found that patient outcomes, even in specialized rheumatology clinics, are typically poor $[9,10]$.

Poor treatment outcomes have led to frustration among patients and their clinicians, and contributed to 
the impact of fibromyalgia on disability [11-13]. Observational studies have found that $20 \%$ to $50 \%$ of persons with fibromyalgia report that they are unable to work or that they can work only a few days per month, and $27 \%$ to $55 \%$ receive disability or social security payments. Of those that do work, $36 \%$ experience an average of two or more absences from work per month [11-13].

Physicians typically find fibromyalgia difficult to manage and patients with fibromyalgia are likely to be dissatisfied with treatment [14]. A recent survey of 1,200 primary care physicians in the United States (33\% response rate) found that only $14 \%$ of respondents indicated very good or excellent satisfaction with managing patients with fibromyalgia and other medically unexplained symptoms [15], and a study of 400 British general practitioners ( $75 \%$ response rate) found that only $44 \%$ of respondents felt there were effective treatment options available for this population [16].

There have been no less than 38 systematic reviews addressing therapies for fibromyalgia [17-54]; however, the large majority of reviews to date have explored therapies in isolation or looked at a subgroup of treatments. There have been two network meta-analyses we are aware of that explored multiple therapies for fibromyalgia [51,52]. The first [52] restricted comparisons to pharmacological treatments only and used the Jadad scale to assess study quality [55], which has been criticized as overly simplistic and placing too much emphasis on blinding [56]. The second [51] excluded complementary and alternative medicine approaches, had no assessment of study quality, and summarized continuous data using the standardized mean difference, which is vulnerable to differential variability in populations enrolled and adds challenges in interpreting the magnitude and importance of treatment effects [57,58]. No review has looked at all interventional studies for fibromyalgia, which limits attempts to make inferences regarding the relative effectiveness of available treatments. Further, none used the GRADE framework to establish confidence in pooled estimates of treatment effect [59].

We will explore all therapies for fibromyalgia that have been tested in randomized controlled trials (RCTs) and use Bayesian mixed treatment comparison methods (adjusted indirect comparisons) to complement the direct comparisons of the relative effects of competing interventions in RCTs $[60,61]$.

\section{Methods/design}

\section{Protocol and registration}

Our protocol is registered on PROSPERO (CRD4201200 3291), http://www.crd.york.ac.uk/PROSPERO.

Our paper conforms to the PRISMA guidelines for reporting systematic reviews [62].

\section{Eligibility criteria}

Trials eligible for our review will (1) have enrolled adult patients ( $\geq 18$ years of age) presenting with fibromyalgia or a related condition (for example, myofascial pain syndrome, fibrositis, fibromyositis, muscular rheumatism, chronic generalized pain syndrome), and (2) have randomized patients to an intervention or a control arm.

\section{Information sources and search}

We will identify relevant RCTs, in any language, by a systematic search of CINAHL, EMBASE, MEDLINE, AMED, HealthSTAR, PsycINFO, PapersFirst, ProceedingsFirst, and the Cochrane Central Registry of Controlled Trials, from inception of the database, with relevant $\mathrm{MeSH}$ headings. An experienced librarian (QM) developed a sensitive search strategy for each individual database (see Additional file 1). We will scan the bibliographies of all retrieved trials and other relevant publications, including reviews and meta-analyses, for additional relevant articles.

\section{Study selection}

Twenty reviewers with experience in health research methodology will work in pairs to screen, independently and in duplicate, titles and available abstracts of identified citations and acquire the full text publication of any article that either reviewer judge as potentially eligible. The same reviewer teams will independently apply eligibility criteria to the full text of potentially eligible trials. Reviewers will resolve disagreements by consensus or, if a discrepancy remains, through discussion with one of two arbitrators (JWB or GHG).

\section{Data collection process and data items}

Using standardized forms (see Additional file 2) and a detailed instruction manual that will be used to inform specific tailoring of an online data abstraction program (DistillerSR), ten teams of reviewers will extract data independently and in duplicate from each eligible study. To ensure consistency across reviewers, we will conduct calibration exercises before starting the review. Data abstracted will include demographic information, methodology, intervention details, and all reported patient-important outcomes. Reviewers will resolve disagreements by discussion, and one of two arbitrators (JWB or GHG) will adjudicate unresolved disagreements. We will contact study authors to resolve any uncertainties.

Two reviewers (GC, EAC) will independently extract details on interventions and outcomes from all RCTs in order to classify them into common intervention categories. The abstractors will develop the categories independently and then achieve consensus through discussion. Outcomes will be classified into domains, based on the 
guidelines published by the Initiative on Methods, Measurement, and Pain Assessment in Clinical Trials (IMMPACT) [63-70]. These consist of nine domains: pain; physical and emotional functioning (including Quality of Life); participant rating of improvement and satisfaction with treatment; adverse events; participant disposition (for example, adherence to the treatment regime and reasons for premature withdrawal from the trial); role functioning (that is, work and educational activities, social and recreational activities, home and family care); interpersonal functioning (that is, interpersonal relationships, sexual activities); sleep; and fatigue.

\section{Risk of bias in individual studies}

Reviewers will assess risk of bias within each study with a modified Cochrane risk of bias instrument which assesses the following key domains: sequence generation; allocation concealment; blinding of participants, healthcare professionals, outcome assessors, data collectors, and data analysts; incomplete outcome data; selective outcome reporting; and other sources of bias. Reviewers will input response options of 'definitely yes', 'probably yes', 'probably no', and 'definitely no' for each of the domains, with 'definitely yes' and 'probably yes' ultimately assigned low risk of bias and 'definitely no' and 'probably no' assigned high risk of bias [71]. Reviewers will resolve disagreements by discussion, and one of two arbitrators (JWB or GHG) will adjudicate unresolved disagreements.

\section{Direct comparisons meta-analyses}

To pool outcome data for trials that compare the same intervention with the same comparator, we will use random effects meta-analyses, which are conservative in that they consider both within and among study differences in calculating the error term used in the analysis [11]. We will pool cross-over trials with parallel design RCTs, using methods outlined in the Cochrane handbook to derive effect estimates [72]. Specifically, we will perform a paired $t$-test for each cross-over trial if either of the following are available: 1 ) the individual participant data; 2) the mean and SD (or standard error) of the participant-specific differences between the intervention and control measurements; 3) the mean difference and one of the following: (i) a t-statistic from a paired $t$-test, (ii) a p-value from a paired $t$-test, or (iii) a confidence interval from a paired analysis; or 4) a graph of measurements of the intervention arm and control arm from which we can extract individual data values (pending that the matched measurements for each individual can be identified) [72]. If these data are not available, we will approximate paired analyses by first calculating the mean difference for the paired analysis $\left(\mathrm{MD}=\mathrm{M}_{\mathrm{E}}-\mathrm{M}_{\mathrm{C}}\right)$ and the standard error of the mean difference:
$S E(M D)=\frac{S D_{\text {diff }}}{\sqrt{N}}$, where $\mathrm{N}$ represents the number of participants in the trial, and $\mathrm{SD}_{\text {diff }}$ represents the standard deviation of within-participant differences between the intervention and control measurements [72]. If the standard error or standard deviation of within-participant differences is not available, we will impute the standard deviation using methods outlined in the Cochrane Handbook [73].

\section{Ensuring interpretable results from pooled estimates of effect}

We will use a number of approaches to facilitate interpretable results from our meta-analyses. For trials that report dichotomous outcomes, we will calculate the odds ratio (OR) to inform relative effectiveness. We will acquire estimates of baseline risk from observational studies or, if not available, from the median of the control group from eligible RCTs.

When pooling across trials that report continuous outcomes using the same instrument, we will calculate the weighted mean difference (WMD), which maintains the original unit of measurement and represents the average difference between groups [74]. Once the WMD has been calculated, we will contextualize this value by noting the corresponding minimally important difference (MID) - the smallest change in instrument score that patients perceive is important. We will prioritize use of anchor-based MIDs when available, and calculate distribution-based MIDs when they are not.

Contextualizing the WMD through the MID can be misleading because clinicians may interpret a WMD less than the MID as suggesting that no patient obtains an important benefit, which is not accurate. Therefore, we will generate an estimate of the proportion of patients who have benefited by applying the MID to individual studies, estimating the proportions who benefit in each study, and then aggregate the results in order to provide a summary estimate of the proportion of patients who benefit from treatment across all studies. Details of the methods by which we will conduct this analysis are presented immediately below in our discussion of situations in which investigators have used different instruments to measure the same construct.

For trials that use different continuous outcome measures that address the same underlying construct, one cannot calculate a weighted mean difference, and we will therefore calculate a measure of effect called the standardized mean difference (SMD) or 'effect size'. This involves dividing the difference between the intervention and control means in each trial (that is, the mean difference) by the estimated between-person standard deviation (SD) for that trial. The SMD expresses the intervention effect in SD units rather than the original units of measurement, with the value of a SMD 
depending on both the size of the effect (the difference between means) and the SD of the outcomes (the inherent variability among participants).

This common approach to pooling continuous outcome data is often problematic. If the heterogeneity of patients is different across studies, the SD will vary across studies. Therefore, given the same true difference in outcome between intervention and control groups, trials with more heterogeneous patients will show apparently - but spuriously - smaller effects than trials enrolling less heterogeneous patients. Furthermore, interpretation of the magnitude of effect when represented as SD units is not intuitive.

In order to address these issues, we will contextualize the SMD value through MID units, which are not vulnerable to the distortions that varying heterogeneity of populations can create and are more interpretable to both clinicians and patients $[58,75]$. For outcome measures that have an established anchor-based MID we will use this measure to convert the summary effect into OR. We will complement this presentation by either converting the summary effect into natural units of a widely accepted instrument used to measure changes in the domain of interest or, if such an instrument is not available, we will substitute the MID for the SD (denominator) in the SMD equation, which will result in more readily interpretable MID units instead of SD units [58]. Finally, we will, as for SMD, provide a summary estimate of the proportion of patients who benefit from treatment across all studies

We illustrate this approach with the following example. We will first describe how we will summarize the outcome in MID units. Assume that a trial reports a mean difference (MD) on a continuous outcome measure " $\mathrm{X}$ ", and assume that an anchor-based MID for instrument $\mathrm{X}, \mathrm{MID}_{\mathrm{X}}$, has been established. The estimated MD is a random variable. If we standardize this random variable by dividing it by the $\mathrm{MID}_{\mathrm{X}}$, we get a new random variable, $\mathrm{MD} / \mathrm{MID}_{\mathrm{X}}$. We know from basic probability theory that because $\mathrm{MID}_{\mathrm{X}}$ is a constant, the variance of $M D / M I D_{X}$ is given by:

$$
\operatorname{Var}\left(\frac{M D}{M I D_{X}^{2}}\right)=\frac{\operatorname{Var}(M D)}{M I D_{X}^{2}}
$$

That is, the variance of the mean difference divided by the square of the MID. Further, the standard error of $\mathrm{MD} / \mathrm{MID}_{\mathrm{X}}$ is given by:

$$
S E\left(\frac{M D}{M I D_{X}^{2}}\right)=\sqrt{\frac{\operatorname{Var}(M D)}{M I D_{X}^{2}}}=\frac{S E(S D)}{M I D_{X}}
$$

Consider a meta-analysis that included $\mathrm{k}$ trials. The first $\mathrm{j}$ trials use disease-specific instrument $\mathrm{A}$, and the last $k-j$ trials use disease-specific instrument $B$. Let $M D_{i}$ denote the mean difference observed in trial $\mathrm{i}$, let $\mathrm{MID}_{\mathrm{A}}$ denote the MID established for instrument A, and let $\mathrm{MID}_{\mathrm{B}}$ denote the MID established for instrument B. Further, let $\mathrm{m}_{\mathrm{i}}$ denote the MID standardized effect for trial $\mathrm{i}$. To pool results across trials using MIDs we must first estimate the $\mathrm{m}_{\mathrm{i}}$ and its associated variance for all trials. For $\mathrm{i}=1, \ldots, \mathrm{j}$ we have:

$$
m_{i}=\frac{M D_{i}}{M I D_{A}} \quad \text { and } \quad \operatorname{Var}\left(m_{i}\right)=\frac{\operatorname{Var}\left(M D_{i}\right)}{M I D_{A}^{2}}
$$

and for $i=j+1, \ldots, k$ we have:

$$
m_{i}=\frac{M D_{i}}{M I D_{B}} \quad \text { and } \quad \operatorname{Var}\left(m_{i}\right)=\frac{\operatorname{Var}\left(M D_{i}\right)}{M I D_{B}^{2}}
$$

By defining the trial weights as $\mathrm{w}_{\mathrm{i}}=\operatorname{Var}\left(\mathrm{m}_{\mathrm{i}}\right)^{-1}$, we can use the fixed-effect model inverse variance method to pool the MID-standardized mean differences using the formula:

$$
\hat{m}=\left(\sum_{i=1}^{k} w_{i} \cdot m_{i}\right) /\left(\sum_{i=1}^{k} w_{i}\right)
$$

Where $\hat{m}$ denotes the pooled MID-standardized mean difference. The standard error of $\hat{m}$ can be calculated using the formula:

$$
\operatorname{se}(\hat{m})=1 /\left(\sum_{i=1}^{k} w_{i}\right)
$$

The associated confidence intervals can subsequently be derived. MID-standardized mean differences can also be combined in a random-effects model using weights $\mathrm{w}_{\mathrm{i}}=\left(\operatorname{Var}\left(\mathrm{m}_{\mathrm{i}}\right)+\mathrm{T}^{2}\right)^{-1}$, where $\tau^{2}$ denotes the between-trial variance.

This presentation does not address the risk that clinicians may interpret all mean effects below the MID as unimportant, and presume important benefit for all patients when mean effects exceeds the MID. We will address this issue by assuming normal distributions of data and then calculating the proportions of participants in the intervention and control groups in each study that demonstrated an improvement greater than the MID [76]. The results are then pooled across studies. If we only have post-test data (rather than magnitude of change), we will apply this approach if evidence exists regarding meaningful thresholds. For instance, if one knows that people with scores of less than 8 on the Hamilton rating scale for depression (HAM-D) are considered to be not depressed, one could examine the proportion of individuals below that threshold.

If such meaningful thresholds do not exist, we will use post-test data and assume that the minimally important 
change within an individual corresponds, on average, to the minimally important difference between individuals. Making this assumption, one can calculate the difference in the proportion who benefit in intervention and control. To do this, we will take the mean value in the control group plus one MID unit, and calculate the proportion of patients in each group above that threshold.

If an anchor-based MID has not been established for all instruments, we will assume a meta-analysis control group probability $\left(p_{C}\right)$ and use the SMD to calculate the OR. Specifically, we will construct a conceptual metaanalysis control group with mean $\mu_{C}$, standard deviation $\sigma_{C}$, and group size $n_{C}$, and a conceptual meta-analysis intervention group with mean $\mu_{E}$, standard deviation $\sigma_{E}$, and group size $n_{E}$ such that the SMD can be represented as $S M D=\mu_{E}-\mu_{C}$ and $\sigma_{E}=\sigma_{C}=1$. We will set $\mu_{C}=0$ and $\sigma_{C}=1$, and our threshold $(T)$ will be equal to $\Phi^{-1}\left(p_{C}\right)$, where $\Phi^{-1}$ is the inverse standard normal cumulative distribution function. We will then use the derived threshold to calculate the conceptual intervention group probability $\left(p_{E}\right)$. The intervention group mean response is assumed to follow a normal distribution with mean SMD and a SD of 1 . Thus, the intervention group probability is $p_{E}=1-\Phi(T-S M D)$. Having estimated the conceptual meta-analysis control and intervention group probabilities from the pooled SMD, we will calculate the OR as follows:

$$
O R=\frac{p_{E}\left(1-p_{C}\right)}{p_{C}\left(1-p_{E}\right)}
$$

To calculate the $95 \% \mathrm{CI}$, we will use the above formulas substituting the upper and lower bounds of the SMD confidence interval. We will complement this presentation by converting the SMD into natural units of a widely accepted instrument used to measure changes in the domain of interest or, if such an instrument is not available, we will calculate the ratio of means [58].

\section{Assessment of heterogeneity and subgroup analyses}

We will examine heterogeneity of meta-analyses using both a chi-squared test and the $\mathrm{I}^{2}$ statistic, the percentage of among-study variability that is due to true differences between studies (heterogeneity) rather than sampling error (chance) $[77,78]$. We have generated the following a priori hypotheses to explain variability between studies: (1) interventions will show larger effects among trials enrolling $\geq 50 \%$ patients clearly defined as meeting the American College of Rheumatology (ACR) criteria for fibromyalgia [1] versus trials in which less than $50 \%$ of subjects meet the ACR criteria; (2) larger effects in trials of patients in which receipt of disability benefits or involvement in litigation was an exclusion criteria versus those that did not exclude patients on this basis; and (3) studies with greater risk of bias will have larger effects than studies with lower risk of bias. We will perform subgroup analyses on a component-by-component basis if we detect variability within the individual risk of bias components. We will conduct z-tests [79] to establish if subgroups differ significantly from each other [80].

\section{Multiple comparison meta-analysis}

We will examine the assumptions of similarity (for an indirect treatment comparison) and consistency (for mixed-treatment comparison) before conducting a network meta-analysis. To assess relative effects of competing treatments, we will construct a random effects model within the Bayesian framework using Markov chain Monte Carlo methods in WinBUGS (MRC Biostatistics Unit, Cambridge, UK) [81]. We will model outcomes in every treatment group of every study and specify the relations among the effect sizes across studies [82]. This method combines direct and indirect evidence for any given pair of treatments. We will use the resulting 95\% credible intervals (CrIs) to assess treatment effects [83]. We will assess the probability that each treatment was the most efficacious regimen, the second best, the third best, etcetera, by calculating the effect size for each treatment compared with an arbitrary common control group and counting the proportion of iterations of the Markov chain in which each treatment has the highest effect size, the second highest, etcetera. A key assumption behind multiple treatments metaanalysis is that the analyzed network is consistent; that is, that direct and indirect evidence on the same comparisons do not disagree beyond chance. We will locate and estimate inconsistencies by employing a mixed treatment comparisons inconsistency model in the Bayesian framework [84].

We will use a recent user's guide published in the Journal of American Medical Association (of which two of our team were authors: KT and GHG) to assess the strength of inferences and credibility of our network meta-analysis [85]. We will use this guide to critically appraise our work in 3 domains and 12 subdomains (Table 1).

\section{Confidence in pooled estimates of effect}

Reviewers will, independently and in duplicate, assess the confidence in effect estimates for all outcomes using the GRADE (Grading of Recommendations, Assessment, Development and Evaluation) rating system [86]. In the GRADE system of rating quality of evidence for each outcome, randomized trials begin as high quality evidence, but may be rated down by one or more of five categories of limitations: (1) risk of bias, (2) consistency, (3) directness, (4) imprecision, and (5) reporting bias [80]. After considering these categories, the confidence 
Table 1 Critical appraisal guide for a Network Meta-Analysis [85]

\begin{tabular}{ll}
\hline \begin{tabular}{l} 
Critical appraisal criteria \\
\hline A. Are the results of the study valid?
\end{tabular} \\
\hline & Did the review explicitly address a sensible clinical question? \\
\hline & Was the search for relevant studies exhaustive? \\
\hline B. What are the results? & Were there major biases in the primary studies? \\
\hline & What was the amount of evidence in the network? \\
\hline & Were the results similar from study to study? \\
\hline & Were the results consistent in direct and indirect comparisons? \\
\hline C. How can I apply the results to patient care? & What were the overall treatment effects and their uncertainty, and how did the treatments rank? \\
\hline & Were the results robust to sensitivity assumptions and potential biases? \\
\hline & Were all patient-important outcomes considered? \\
\hline & Were all potential treatment options considered? \\
\hline & Are any postulated subgroup effects credible? \\
\hline & What is the overall quality and what are limitations of the evidence? \\
\hline
\end{tabular}

in estimates for each outcome will be categorized as follows: 'high' quality of evidence (we are very confident that the true effect lies close to that of the estimate of the effect); 'moderate' quality of evidence (we are moderately confident in the effect estimate and the true effect is likely to be close to the estimate of the effect, but there is a possibility that it is substantially different); 'low' quality of evidence (our confidence in the effect estimate is limited and the true effect may be substantially different from the estimate of the effect); and 'very low' quality of evidence (we have very little confidence in the effect estimate and the true effect is likely to be substantially different from the estimate of effect) [86].

We will assess publication bias by visually observing asymmetry of the funnel plot for each outcome. As a rule of thumb [87], tests for funnel plot asymmetry should be used only when there are at least ten studies included in the meta-analysis. Otherwise the power of the tests is too low to distinguish chance from real asymmetry. We will report our results by type of intervention (for example, psychotherapy, analgesics, antidepressants) and focus on patient-important outcomes. We will report all direct comparison data, and only complement these data with indirect comparison data if the strength of inferences from direct comparisons is similar or less than the strength of inferences from indirect comparisons. If there are no direct comparisons available, we will report indirect comparison data only.

\section{Knowledge translation}

We plan to create a stakeholder advisory committee with representation from ambulatory health care providers from across Ontario, Canada as well as from key organizations. We will ensure that we have geographically diverse representation including primary care providers who practice in rural areas of the province. Members of our stakeholder committee will be invited to attend our planning meeting and share their input/advice with members of the review team.

Our team also will engage in an end-of-study knowledge translation workshop. The purpose of this activity will be to share our findings with key relevant stakeholders (researchers, clinicians and decision-makers) in order to identify future opportunities for dissemination, beyond traditional peer-reviewed publications, with our stakeholders, discuss how to maximize uptake of our findings in patient education and clinical practice, and determine future research directions. The overall goal of the workshop is to develop an agenda that will establish directions to develop and implement our research findings into practice.

The following strategies will be used to promote awareness of the stakeholder meeting findings according to the Ottawa Model of Research Use in which information is tailored to specific audiences: (1) distribution of findings to all involved participants for further input, sharing within their organization, and for sharing with their own stakeholders via newsletter, web site, or other methods; (2) presentation at relevant peer-reviewed and community conferences; and (3) publication in an opensource peer-reviewed journal. We anticipate that this meeting will identify new areas of inquiry for research and practice, such as the development of new educational tools for patients and clinicians. We also anticipate that new collaborations and networks will be created that will support the identified work going forward. Any groups identified through the meeting will be included as part of the report back to the stakeholders in order to broadly disseminate the findings. 


\section{Discussion}

Our review will evaluate all treatments for fibromyalgia, provide relative effectiveness of treatments, and evaluate the quality of the evidence in a thorough and consistent manner using the GRADE approach [88-90]. Additionally, many existing reviews focus on surrogate outcomes, such as number of tender points, stiffness, range of motion, or laboratory values; we will prioritize patientimportant outcomes such as function and quality of life. The results of our systematic review will be of interest to a broad audience including patients diagnosed with fibromyalgia, health professionals managing fibromyalgia, employers, human resource professionals, insurers/ compensation boards, and labor groups. Our review will facilitate evidence-based management of patients with fibromyalgia, identify key areas for future research, and provide a framework for conducting large systematic reviews involving indirect comparisons.

\section{Additional files}

Additional file 1: Appendix A. Search Strategy.

Additional file 2: Appendix B. Data Abstraction Forms.

\section{Abbreviations}

Crls: Credible intervals; GRADE: Grading of Recommendations, Assessment, Development and Evaluation; MD: Mean difference; MID: Minimally important difference; OR: Odds ration; RCTs: Randomized controlled trials; SD: Standard deviation; SMD: Standardized mean difference; WMD: Weighted mean difference.

\section{Competing interests}

JWB acts as a consultant to Prisma Health Canada, a private incorporated company funded by employers and insurers that consults on and manages long-term disability claims. All other authors report no conflicts of interest.

\section{Authors' contributions}

JWB, KT and GHG conceived the study design. JWB and SE completed the first draft of the manuscript. All authors reviewed several drafts of the manuscript and approved the final version.

\section{Acknowledgements}

This systematic review is funded by a Canadian Institutes of Health Research Knowledge Synthesis Grant. The development of this protocol was funded in-part by a grant from the Ontario Chiropractic Association. JWB is supported by a New Investigator Award from the Canadian Institutes of Health Research and Canadian Chiropractic Research Foundation. SE is supported by a Canadian Institutes of Health Research Doctoral Award. JJR is supported by an award from the NCMIC Foundation.

\section{Author details}

'Department of Anesthesia, McMaster University, 1200 Main Street West, Hamilton, Ontario L8S 4K1, Canada. ${ }^{2}$ Department of Clinical Epidemiology and Biostatistics, McMaster University, 1200 Main Street West, Hamilton, Ontario L8S 4K1, Canada. ${ }^{3}$ Canadian Memorial Chiropractic College, 6100 Leslie Street, Toronto, Ontario M2H 3J1, Canada. ${ }^{4}$ Faculty of Medicine, University of Toronto, 1 Kings College Circle, Toronto, Ontario M5S 1A8, Canada. ${ }^{5}$ Faculty of Kinesiology and Health Studies, University of Regina, 3737 Wascana Parkway, Regina, Saskatchewan S4S OA2, Canada. ${ }^{6}$ School of Rehabilitation Sciences, McMaster University, 1400 Main Street West, Hamilton, Ontario L8S 1C7, Canada. ${ }^{7}$ German Hospital, Av. Pueyrredón 1640 (C1118 AAT), Buenos Aires, Argentina. ${ }^{8}$ Department of Family Medicine, McMaster University, McMaster Innovation Park, 175 Longwood Road South,
}

Hamilton, Ontario L8P OA1, Canada. 'Department of Orthopaedic Surgery, Academic Medical Center, Meibergdreef 9, 1105, Amsterdam-Zuidoost, the Netherlands. ${ }^{10}$ Ontario Chiropractic Association, 20 Victoria Street, Suite 200, Toronto, Ontario M5C 2N8, Canada. ${ }^{11}$ The Institute for Work \& Health, 481 University Avenue, Toronto, Ontario M5G 2E9, Canada. ${ }^{12}$ Dalla Lana School of Public Health, University of Toronto, 6th floor, 155 College Street, Toronto, Ontario M5T 3M7, Canada. ${ }^{13}$ Stanford Prevention Research Center, Stanford University School of Medicine, 1265 Welch Road, Stanford, CA 94305-5411, USA. ${ }^{14}$ Knowledge and Evaluation Research Unit, Divisions of Endocrinology and Diabetes and Health Care and Policy Research, Mayo Clinic, 200 First Street SW, Rochester, MN 55905, USA. ${ }^{15}$ Faculty of Health Sciences, McMaster University, 1280 Main Street West, Hamilton, Ontario L8S 4K1, Canada. ${ }^{16}$ 2nd Department of Internal Medicine, Jagiellonian University Medical College, ul Skawinska 8, 31-066, Kraków, Poland. ${ }^{17}$ Polish Institute of Evidence Based Medicine, ul. Krakowska 41, 31-066, Kraków, Poland. ${ }^{18}$ Academy of Swiss Insurance Medicine, University Hospital Basel, Schanzenstrasse 55, 4031, Basel, Switzerland.

Received: 25 January 2013 Accepted: 22 February 2013

Published: 13 March 2013

\section{References}

1. Wolfe F, Smythe HA, Yunus MB, Bennett RM, Bombardier C, Goldenberg DL, Tugwell P, Campbell SM, Abeles M, Clark P, Fam AG, Farber SJ, Fiechtner JJ, Franklin CM, Gatter RA, Hamaty D, Lessard J, Lichtbroun AS, Masi AT, McCain GA, Reynolds WJ, Romano TJ, Russell IJ, Sheon RP: The American College of Rheumatology 1990 Criteria for the Classification of Fibromyalgia. Report of the Multicenter Criteria Committee. Arthritis Rheum 1990, 33:160-172.

2. Wolfe F, Ross K, Anderson J, Russell IJ, Hebert L: The prevalence and characteristics of fibromyalgia in the general population. Arthritis Rheum 1995, 38:19-28.

3. Assumpção A, Cavalcante AB, Capela CE, Sauer JF, Chalot SD, Pereira CA, Marques AP: Prevalence of fibromyalgia in a low socioeconomic status population. BMC Musculoskelet Disord 2009, 10:64.

4. Branco JC, Bannwarth B, Failde I, Abello Carbonell J, Blotman F, Spaeth M, Saraiva F, Nacci F, Thomas E, Caubère JP, Le Lay K, Taieb C, Matucci-Cerinic M: Prevalence of fibromyalgia: a survey in five European countries. Semin Arthritis Rheum 2010, 39:448-453.

5. Carmona L, Ballina J, Gabriel R, Laffon A, on behalf of the EPISER Study Group: The burden of musculoskeletal diseases in the general population of Spain: results from a national survey. Ann Rheum Dis 2001, 60:1040-1045

6. Cöster L, Kendall S, Gerdle B, Henriksson C, Henriksson KG, Bengtsson A: Chronic widespread musculoskeletal pain. A comparison of those who meet criteria for fibromyalgia and those who do not. Eur J Pain 2008, 12:600-610.

7. Salaffi F, De Angelis R, Grassi W, MArche Pain Prevalence INvestigation Group (MAPPING) study: Prevalence of musculoskeletal conditions in an Italian population sample: results of a regional community-based study. I. The MAPPING study. Clin Exp Rheumatol 2005, 23:819-828.

8. White KP, Speechley M, Harth M, Ostbye T: The London Fibromyalgia Epidemiology Study: the prevalence of fibromyalgia syndrome in London, Ontario. J Rheumatol 1999, 26:1570-1576.

9. Nöller V, Sprott H: Prospective epidemiological observations on the course of the disease in fibromyalgia patients. J Negat Results Biomed 2003, 2:4-9.

10. Wolfe F, Anderson J, Harkness D, Bennett RM, Caro XJ, Goldenberg DL, Russell $\mathrm{J}$, Yunus MB: Health status and disease severity in fibromyalgia: results of a six-center longitudinal study. Arthritis Rheum 1997, 40:1571-1579.

11. Ledingham J, Doherty S, Doherty M: Primary fibromyalgia syndrome - An outcome study. Br J Rheumatol 1993, 32:139-142.

12. Wolfe F, Anderson J, Harkness D, Bennett RM, Caro XJ, Goldenberg DL, Russell IJ, Yunus MB: Work and disability status of persons with fibromyalgia. J Rheumatol 1997, 24:1171-1178.

13. Martinez JE, Ferraz MB, Sato El, Atra E: Fibromyalgia versus rheumatoid arthritis: a longitudinal comparison of the quality of life. J Rheumatol 1995, 22:270-274.

14. Sharpe M, Mayou R, Seagroatt V, Surawy C, Warwick H, Bulstrode C, Dawber $\mathrm{R}$, Lane D: Why do doctors find some patients difficult to help? Q J Med 1994, 87:187-193. 
15. Hartz AJ, Noyes R, Bentler SE, Damiano PC, Willard JC, Momany ET: Unexplained symptoms in primary care: perspectives of doctors and patients. Gen Hosp Psychiatry 2000, 22:144-152.

16. Reid S, Whooley D, Crayford T, Hotopf M: Medically unexplained symptoms - GPs' attitudes towards their cause and management. Fam Pract 2001, 18:519-523.

17. Alegre DM, Alejandra-Pereda C, Betina-Nishishinya M, Rivera J: Systematic review of pharmacologic treatment in fibromyalgia. Medicina Clinica 2005, 125:784-787.

18. Arnold B, Häuser W, Bernardy K, Brückle W, Friedel E, Köllner V, Kühn-Becker H, Richter M, Weigl M, Weiss T, Offenbächer M: Multicomponent therapy for treatment of fibromyalgia syndrome. Schmerz 2008, 22:334-338.

19. Busch AJ, Schachter CL, Peloso PM: Fibromyalgia and exercise training: a systematic review of randomized clinical trials. Phys Ther Rev 2001, 6:287-306.

20. Busch AJ, Schachter CL, Overend TJ, Peloso PM, Barber KA: Exercise for fibromyalgia: a systematic review. J Rheumatol 2008, 35:1130-1144.

21. Ernst E: Chiropractic treatment for fibromyalgia: a systematic review. Clin Rheumatol 2009, 28:1175-1178.

22. Garcia-Campayo J, Magdalena J, Magallón R, Fernández-García E, Salas M, Andrés $E$ : A meta-analysis of the efficacy of fibromyalgia treatment according to level of care. Arthritis Res Ther 2008, 10:R81.

23. Goldenberg DL, Burckhardt C, Crofford L: Management of fibromyalgia syndrome. JAMA 2004, 292:2388-2395.

24. Häuser W, Bernardy K, Uçeyler N, Sommer C: Treatment of fibromyalgia syndrome with gabapentin and pregabalin - A meta-analysis of randomized controlled trials. Pain 2009, 145:69-81.

25. Häuser W, Bernardy K, Arnold B, Offenbächer M, Schiltenwolf M: Efficacy of multicomponent treatment in fibromyalgia syndrome: a meta-analysis of randomized controlled clinical trials. Arthritis Rheum 2009, 61:216-224.

26. Häuser W, Bernardy K, Uçeyler N, Sommer C: Treatment of fibromyalgia syndrome with antidepressants: a meta-analysis. JAMA 2009, 301:198-209.

27. Jones KD, Adams D, Winters-Stone K, Burckhardt CS: A comprehensive review of 46 exercise treatment studies in fibromyalgia (1988-2005). Health Qual Life Outcomes 2006, 4:67.

28. Langhorst J, Häuser W, Irnich D, Speeck N, Felde E, Winkelmann A, Lucius H, Michalsen A, Musial F: Alternative and complementary therapies in fibromyalgia syndrome. Schmerz 2008, 22:324-333.

29. Martin-Sanchez E, Torralba E, Díaz-Domínguez E, Barriga A, Martin J: Efficacy of acupuncture for the treatment of fibromyalgia: systematic review and meta-analysis of randomized trials. Open Rheumatol 2009, 3:25-29.

30. Mayhew E, Ernst E: Acupuncture for fibromyalgia-a systematic review of randomized clinical trials. Rheumatology 2007, 46:801-804

31. McVeigh JG, McGaughey H, Hall M, Kane P: The effectiveness of hydrotherapy in the management of fibromyalgia syndrome: a systematic review. Rheumatol Int 2008, 29:119-130.

32. Nishishinya B, Urrútia G, Walitt B, Rodriguez A, Bonfill X, Alegre C, Darko G: Amitriptyline in the treatment of fibromyalgia: a systematic review of its efficacy. Rheumatology (Oxford) 2008, 47:1741-1746.

33. Oliver K, Cronan TA, Walen HR: A review of multidisciplinary interventions for fibromyalgia patients: where do we go from here? J Muscoskel Pain 2001, 9:63-80.

34. Schiltenwolf M, Häuser W, Felde E, Flügge C, Häfner R, Settan M, Offenbächer M: Physiotherapy, exercise and strength training and physical therapies in the treatment of fibromyalgia syndrome. Schmerz 2008, 22:303-312.

35. Schneider M, Vernon H, Ko G, Lawson G, Perera J: Chiropractic management of fibromyalgia syndrome: a systematic review of the literature. J Manipulative Physiol Ther 2009, 32:25-40.

36. Sim J, Adams N: Systematic review of randomized controlled trials of nonpharmacological interventions for fibromyalgia. Clin J Pain 2002, 18:324-336.

37. Sommer $C$, Häuser W, Berliner M, Brückle W, Ehlers S, Mönkemöller $K$, Moradi B, Petzke F, Uçeyler N, Wörz R, Winter E, Nutzinger DO: Pharmacological treatment of fibromyalgia syndrome. Schmerz 2008, 22:313-323.

38. Sultan A, Gaskell H, Derry S, Moore RA: Duloxetine for painful diabetic neuropathy and fibromyalgia pain: systematic review of randomised trials. BMC Neurol 2008, 8:29.
39. Thieme K, Häuser W, Batra A, Bernardy K, Felde E, Gesmann M, Illhardt A, Settan M, Wörz R, Köllner V: Psychotherapy in patients with fibromyalgia syndrome. Schmerz 2008, 22:295-302

40. Thomas $\mathrm{E}$, Blotman F: Are antidepressants effective in fibromyalgia? Joint Bone Spine 2002, 69:531-533.

41. Tofferi JK, Jackson JL, O'Malley PG: Treatment of fibromyalgia with cyclobenzaprine: A meta-analysis. Arthritis Rheum 2004, 51:9-13.

42. Uceyler N, Hauser W, Sommer C: A systematic review on the effectiveness of treatment with antidepressants in fibromyalgia syndrome. Arthritis Rheum 2008, 59:1279-1298.

43. Arnold LM, Keck PE Jr, Welge JA: Antidepressant treatment of fibromyalgia. A meta-analysis and review. Psychosomatics 2000, 41:104-113.

44. Hadhazy VA, Ezzo J, Creamer P, Berman BM: Mind-body therapies for the treatment of fibromyalgia. A systematic review. J Rheumatol 2000, 27:2911-2918

45. Karjalainen K, Malmivaara A, van Tulder M, Roine $R$, Jauhiainen $M$, Hurri H, Koes B: Multidisciplinary rehabilitation for fibromyalgia and musculoskeletal pain in working age adults. Cochrane Database Syst Rev 2000, 2, CD001984

46. Merchant $R E$, Andre $C A$ : A review of recent clinical trials of the nutritional supplement Chlorella pyrenoidosa in the treatment of fibromyalgia, hypertension, and ulcerative colitis. Altern Ther Health Med 2001, 7:79-91.

47. O'Malley PG, Jackson JL, Santoro J, Tomkins G, Balden E, Kroenke K: Antidepressant therapy for unexplained symptoms and symptom syndromes. J Fam Pract 1999, 48:980-990.

48. O'Malley PG, Balden E, Tomkins G, Santoro J, Kroenke K, Jackson J: Treatment of fibromyalgia with antidepressants: a meta-analysis. J Gen Intern Med 2000, 15:659-666.

49. Offenbächer M, Stucki G: Physical therapy in the treatment of fibromyalgia. Scand J Rheumatol 2000, 113:78-85.

50. Rossy LA, Buckelew SP, Dorr N, Hagglund KJ, Thayer JF, Mclntosh MJ, Hewett JE, Johnson JC: A meta-analysis of fibromyalgia treatment interventions. Ann Behav Med 1999, 21:180-191.

51. Nüesch E, Häuser W, Bernardy K, Barth J, Jüni P: Comparative efficacy of pharmacological and non-pharmacological interventions in fibromyalgia syndrome: network meta-analysis. Ann Rheum Dis 2012, Jun 27 [Epub ahead of print].

52. Choy E, Marshall D, Gabriel ZL, Mitchell SA, Gylee E, Dakin HA: A systematic review and mixed treatment comparison of the efficacy of pharmacological treatments for fibromyalgia. Semin Arthritis Rheum 2011, 41:335-345.

53. Häuser W, Sarzi-Puttini P, Tölle TR, Wolfe F: Placebo and nocebo responses in randomised controlled trials of drugs applying for approval for fibromyalgia syndrome treatment: systematic review and meta-analysis. Clin Exp Rheumatol 2012, Nov 8 [Epub ahead of print].

54. Hauser W, Bernardy K, Arnold B, Offenbächer M, Schiltenwolf M: Efficacy of multicomponent treatment in fibromyalgia syndrome: a meta-analysis of randomized controlled clinical trials. Arthritis Rheum 2009, 61:216-224.

55. Jadad AR, Moore RA, Carroll D, Jenkinson C, Reynolds DJ, Gavaghan DJ, McQuay HJ: Assessing the quality of reports of randomized clinical trials: Is blinding necessary? Cont Clin Trials 1996, 17:1-12.

56. Berger W: Is the Jadad Score the Proper Evaluation of Trials? J Rheumatol 2006, 33:1710-1712.

57. Sedrakyan A, Shih C: Improving depiction of benefits and harms: analyses of studies of well-known therapeutics and review of high-impact medical journals. Med Care 2007, 45(Suppl 2):S23-S28.

58. Thorlund K, Walter SD, Johnston BC, Furukawa TA, Guyatt GH: Pooling health-related quality of life outcomes in meta-analysis - a tutorial and review of methods for enhancing interpretability. Res Synth Meth 2012, 2:188-203.

59. Guyatt G, Oxman AD, Akl EA, Kunz R, Vist G, Brozek J, Norris S, Falck-Ytter Y, Glasziou P, DeBeer H, Jaeschke R, Rind D, Meerpohl J, Dahm P, Schünemann HJ: GRADE guidelines: 1. Introduction-GRADE evidence profiles and summary of findings tables. J Clin Epidemiol 2011, 64:383-394.

60. Bucher HC, Guyatt GH, Griffith LE, Walter SD: The results of direct and indirect treatment comparisons in meta-analysis of randomized controlled trials. J Clin Epidemiol 1997, 50:683-691.

61. Glenny AM, Altman DG, Song F, Sakarovitch C, Deeks JJ, D’amico R, Bradburn M, Eastwood AJ, International Stroke Trial Collaborative Group: Indirect comparisons of competing interventions. Health Technol Assess 2005, 9:1-134. iii-iv. 
62. Moher D, Liberati A, Tetzlaff J, Altman DG, The PRISMA Group: Preferred Reporting Items for Systematic Reviews and Meta-Analyses: The PRISMA Statement. PLoS Med 2009, 6:e1000097.

63. Turk DC, Dworkin RH, Revicki D, Harding G, Burke LB, Cella D, Cleeland CS, Cowan P, Farrar JT, Hertz S, Max MB, Rappaport BA: Identifying important outcome domains for chronic pain clinical trials: an IMMPACT survey of people with pain. Pain 2008, 137:276-285.

64. Turk DC, Dworkin RH, Burke LB, Gershon R, Rothman M, Scott J, Allen RR, Atkinson JH, Chandler J, Cleeland C, Cowan P, Dimitrova R, Dionne R, Farrar JT, Haythornthwaite JA, Hertz S, Jadad AR, Jensen MP, Kellstein D, Kerns RD, Manning DC, Martin S, Max MB, McDermott MP, McGrath P, Moulin DE, Nurmikko T, Quessy S, Raja S, Rappaport BA, Rauschkolb C, Robinson JP, Royal MA, Simon L, Stauffer JW, Stucki G, et al: Developing patientreported outcome measures for pain clinical trials: IMMPACT recommendations. Pain 2006, 125:208-215.

65. Dworkin R, Turk DC, Farrar JT, Haythornthwaite JA, Jensen MP, Katz NP, Kerns RD, Stucki G, Allen RR, Bellamy N, Carr DB, Chandler J, Cowan P, Dionne R, Galer BS, Hertz S, Jadad AR, Kramer LD, Manning DC, Martin S, McCormick CG, McDermott MP, McGrath P, Quessy S, Rappaport BA, Robbins W, Robinson JP, Rothman M, Royal MA, Simon L, Stauffer JW, Stein W, Tollett J, Wernicke J, Witter J: IMMPACT. Core outcome measures for chronic pain clinical trials: IMMPACT recommendations. Pain 2005, 113:9-19.

66. Turk DC, Dworkin RH, Allen RR, Bellamy N, Brandenburg N, Carr DB, Cleeland C, Dionne R, Farrar JT, Galer BS, Hewitt DJ, Jadad AR, Katz NP, Kramer LD, Manning DC, McCormick CG, McDermott MP, McGrath P, Quessy S, Rappaport BA, Robinson JP, Royal MA, Simon L, Stauffer JW, Stein W, Tollett J, Witter J: Core outcome domains for chronic pain clinical trials: IMMPACT recommendations. Pain 2003, 106:337-345.

67. Dworkin RH, Turk DC, Peirce-Sandner S, Baron R, Bellamy N, Burke LB, Chappell A, Chartier K, Cleeland CS, Costello A, Cowan P, Dimitrova R, Ellenberg S, Farrar JT, French JA, Gilron I, Hertz S, Jadad AR, Jay GW, Kalliomäki J, Katz NP, Kerns RD, Manning DC, McDermott MP, McGrath PJ, Narayana A, Porter L, Quessy S, Rappaport BA, Rauschkolb C, Reeve BB, Rhodes T, Sampaio C, Simpson DM, Stauffer JW, et al: Research design considerations for confirmatory chronic pain clinical trials: IMMPACT recommendations. Pain 2010, 149:177-193.

68. Dworkin RH, Turk DC, McDermott MP, Peirce-Sandner S, Burke LB, Cowan P, Farrar JT, Hertz S, Raja SN, Rappaport BA, Rauschkolb C, Sampaio C: Interpreting the clinical importance of group differences in chronic pain clinical trials: IMMPACT recommendations. Pain 2009, 146:238-244.

69. Turk DC, Dworkin RH, McDermott MP, Bellamy N, Burke LB, Chandler JM, Cleeland CS, Cowan P, Dimitrova R, Farrar JT, Hertz S, Heyse JF, lyengar S, Jadad AR, Jay GW, Jermano JA, Katz NP, Manning DC, Martin S, Max MB, McGrath P, McQuay HJ, Quessy S, Rappaport BA, Revicki DA, Rothman M, Stauffer JW, Svensson O, White RE, Witter J: Analyzing multiple endpoints in clinical trials of pain treatments: IMMPACT recommendations. Initiative on Methods, Measurement, and Pain Assessment in Clinical Trials. Pain 2008, 139:485-493.

70. Dworkin RH, Turk DC, Wyrwich KW, Beaton D, Cleeland CS, Farrar JT Haythornthwaite JA, Jensen MP, Kerns RD, Ader DN, Brandenburg N, Burke LB, Cella D, Chandler J, Cowan P, Dimitrova R, Dionne R, Hertz S, Jadad AR, Katz NP, Kehlet H, Kramer LD, Manning DC, McCormick C, McDermott MP, McQuay HJ, Patel S, Porter L, Quessy S, Rappaport BA, Rauschkolb C, Revicki DA, Rothman M, Schmader KE, Stacey BR, et al: Interpreting the clinical importance of treatment outcomes in chronic pain clinical trials: IMMPACT recommendations. J Pain 2008, 9:105-121.

71. Akl EA, Sun X, Busse JW, Johnston BC, Briel M, Mulla S, You JJ, Bassler D, Lamontagne F, Vera C, Alshurafa M, Katsios CM, Mills E, Guyatt GH: Specific instructions for estimating unclearly reported blinding status in randomized trials were reliable and valid. J Clin Epidemio/ 2012, 65:262-267.

72. The Cochrane Collaboration: 16.4 Cross-over trials. In Cochrane Reviewers' Handbook 5.1.0, Updated March 2011. 16th edition. Edited by Higgins J, Green S. Oxford, UK: Cochrane Collaboration; 2011:14-16.21.

73. The Cochrane Collaboration: 16.1 Missing Data. In Cochrane Reviewers' Handbook 5.1.0, Updated March 2011. 16th edition. Edited by Higgins J, Green S. Oxford, UK: Cochrane Collaboration; 2011:2-16.7.

74. The Cochrane Collaboration: Cochrane Reviewers' Handbook 5.1.0, Updated March 2011. Oxford, UK: Cochrane Collaboration; 2011.
75. Johnston B, Thorlund K, Schünemann HJ, Xie F, Murad MH, Montori VM, Guyatt GH: Improving the interpretation of quality of life evidence in meta-analyses: the application of minimal important difference units. Health Qual Life Outcomes 2010, 8:116.

76. Thorlund K, Walter S, Johnston B, Furukawa TA, Guyatt G: Pooling healthrelated quality of life outcomes in meta-analysis - a tutorial and review of methods for enhancing interpretability. Res Synth Meth 2011, 2:188-203.

77. Higgins JPT, Thompson SG: Quantifying heterogeneity in a meta-analysis. Stat Med 2002, 21:1539-1558.

78. Higgins JPT, Thompson SG, Deeks JJ, Altman DG: Measuring inconsistency in meta-analyses. BMJ 2003, 327:557-560

79. Altman DG, Bland JM: Interaction revisited: The difference between two estimates. BMJ 2003, 326:219.

80. Atkins D, Best D, Briss PA, Eccles M, Falck-Ytter Y, Flottorp S, Guyatt GH, Harbour RT, Haugh MC, Henry D, Hill S, Jaeschke R, Leng G, Liberati A, Magrini N, Mason J, Middleton P, Mrukowicz J, O'Connell D, Oxman AD, Phillips B, Schunemann HJ, Edejer TT, Varonen H, Vist GE, Williams JW Jr, Zaza S, GRADE Working Group: Grading quality of evidence and strength of recommendations. BMJ 2004, 328:1490-1497.

81. Ades AE, Sculpher M, Sutton A, Abrams K, Cooper N, Welton N, Lu G: Bayesian methods for evidence synthesis in cost-effectiveness analysis. Pharmacoeconomics 2006, 24:1-19.

82. Salanti G, Higgins JP, Ades A, loannidis JP: Evaluation of networks of randomized trials. Stat Methods Med Res 2008, 17:279-301.

83. Sterne JA, Davey Smith G: Sifting the evidence - what's wrong with significance tests? BMJ 2001, 322:226-231.

84. LU G, Ades AE: Assessing evidence inconsistency in mixed treatment comparisons. J Am Stat Assoc 2006, 101:447-459.

85. Mills EJ, loannidis JPA, Thorlund K, Schunemann HJ, Puhan MA, Guyatt GH: How to Use an Article Reporting a Multiple Treatment Comparison Meta-analysis. JAMA 2012, 308(12):1246-1253.

86. Guyatt GH, Oxman AD, Vist GE, Kunz R, Falck-Ytter Y, Alonso-Coello P, Schünemann HJ, for the GRADE Working Group: GRADE: an emerging consensus on rating quality of evidence and strength of recommendations. BMJ 2008, 336:924-926.

87. The Cochrane Collaboration: Chapter 10: Addressing reporting biases. In Cochrane Handbook for Systematic Reviews of Interventions (Version 5.0.2). Edited by Higgins J, Thompson SG, Oxford UK:: Cochrane Collaboration; 2010:10.1-10.33

88. Guyatt GH, Oxman AD, Kunz R, Falck-Ytter $Y$, Vist GE, Liberati A, Schünemann HJ, GRADE Working Group: Going from evidence to recommendations. BMJ 2008, 336:1049-1051.

89. Guyatt GH, Oxman AD, Kunz R, Vist GE, Falck-Ytter Y, Schünemann HJ, GRADE Working Group: What is "quality of evidence" and why is it important to clinicians? BMJ 2008, 336:995-998.

90. Guyatt GH, Oxman AD, Vist GE, Kunz R, Falck-Ytter Y, Alonso-Coello P, Schünemann HJ, GRADE Working Group: GRADE: an emerging consensus on rating quality of evidence and strength of recommendations. BMJ 2008, 336:924-926.

doi:10.1186/2046-4053-2-18

Cite this article as: Busse et al.: Systematic review and network metaanalysis of interventions for fibromyalgia: a protocol. Systematic Reviews 2013 2:18.

\section{Submit your next manuscript to BioMed Central and take full advantage of:}

- Convenient online submission

- Thorough peer review

- No space constraints or color figure charges

- Immediate publication on acceptance

- Inclusion in PubMed, CAS, Scopus and Google Scholar

- Research which is freely available for redistribution 